\title{
Systematic screening as a strategy to increase services integration and revenues in Honduras
}

\author{
Ricardo Vernon \\ Population Council \\ James R. Foreit \\ Population Council \\ Fiorella Mancini \\ Suyapa Pavon \\ Jheisy Torres
}

Follow this and additional works at: https://knowledgecommons.popcouncil.org/departments_sbsr-rh

Part of the Demography, Population, and Ecology Commons, International Public Health Commons, Maternal and Child Health Commons, and the Public Health Education and Promotion Commons How does access to this work benefit you? Let us know!

\section{Recommended Citation}

Vernon, Ricardo, James R. Foreit, Fiorella Mancini, Suyapa Pavón, and Jheisy Torres. 2005. "Systematic screening as a strategy to increase services integration and revenues in Honduras," FRONTIERS Final Report. Washington, DC: Population Council. 


\title{
Systematic Screening as a Strategy to Increase Services Integration and Revenues in Honduras
}

\author{
Ricardo Vernon, James R. Foreit, and Fiorella Mancini \\ Frontiers in Reproductive Health Program \\ Suyapa Pavón and Jheisy Torres \\ Honduran Family Planning Association \\ (Asociación Hondureña de Planificación de Familia - ASHONPLAFA)
}

August 2005

This study was funded by the U.S. AGENCY FOR INTERNATIONAL DEVELOPMENT (USAID) under the terms of Cooperative Agreement number HRN-A-00-98-00012-00 and Population Council Subagreement No. AI03.70A. The opinions expressed herein are those of the authors and do not necessarily reflect the views of USAID. 


\section{ABSTRACT}

This operations research study tested the effectiveness of systematic screening to increase the number of services and revenue per visit in a reproductive health program. The Honduras Family Planning Association (Asociación Hondureña de Planificación de Familia - ASHONPLAFA) conducted the study. However, the intervention was not adequately implemented. Only 11 percent of all clients were screened, resulting in no differences in services or revenue per visit. Exit interviews were used as the primary data collection instrument. Both before and after the intervention, clients received about 1.1 services. In contrast, data from a second source, the screening forms, showed that screened clients received a mean of 1.35 services. Thus, it is possible that screened clients may have received more services than clients who were not screened. Relying on evidence derived from the screening forms rather than exit interviews, ASHONPLAFA decided to scale-up the intervention to all agency clinics. 


\section{INTRODUCTION}

Following the 1994 Cairo International Conference on Population and Development (ICPD) Program of Action, the integration of reproductive health services became a priority of many programs. Integration is defined as the proactive provision of multiple reproductive health services in the same facility at the same time (Foreit, Hardee, and Agarwal 2002). There are many reasons why facilities may fail to provide integrated care in reproductive health. This operations research study examines one possible cause: that health providers deliver only the service requested by the client and do not identify other unmet needs. Additionally, clients may be unaware of or do not request services other than the one that caused them to seek care. In any case, even though the services are available at the clinic, the client leaves the facility with unmet reproductive health needs, and the service provider misses an opportunity to render those services. In this study, the Honduran Family Planning Association (Asociación Hondureña de Planificación de Familia - ASHONPLAFA) combined the goal of reducing unmet need with increasing revenues by introducing systematic screening.

Systematic screening is the use of an instrument to identify the client's needs and desires for health services. Screening is done with either a simple checklist or a slightly more elaborate questionnaire. The instrument can be applied when the client first arrives at the clinic by a receptionist, or later on by a service provider. After screening, the client is informed of her additional service needs (if any) and asked if she would like to receive any of the services during her visit, at a later appointment, or a referral if the desired service cannot be provided at the same facility. The technique has been successful in increasing services per visit in six countries in Africa, Asia and Latin America - Bolivia (Foreit, Vernon and Hamel 2005), Guatemala and Mexico (Vernon and Foreit 1999), India (Das et al. 2005), Peru (León et al. 1998), and Senegal (Sanogo et al. 2005).

ASHONPLAFA is a private, non-profit reproductive health service delivery organization providing family planning, general medicine, pediatrics, laboratory tests, gynecology, dentistry, and optometry services through a national chain of 27 clinics. Improved financial sustainability is an important agency goal. The 2003 agency budget was six million dollars, and the proportion of expenses covered by revenues from sales of services and products was 54 percent.

Study objectives included: (1) estimating unmet need for health services among women visiting clinics, and the potential market offered by their family members; and (2) determining if systematic screening increases per visit services and revenue.

\section{METHODOLOGY}

Participants and design: Women ages 15-59 attending five ASHONPLAFA clinics during six-week pre- and post-intervention periods in 2004 participated in the study. A before and after design was used to compare the number of services and revenues per visit. The design does not control for secular trends or seasonality, nor does it protect against confounding factors such as a health promotion campaign during the study. However, the indicator 
services per visit is less subject to variability than number of clients or visits. The potential for confounding was reduced by limiting the study period to sixty days and by conducting the experiment at a time when no health promotion activities were planned. ASHONPLAFA has little experience with service delivery experiments, and the advantages of the design for the agency included its simplicity, short duration, and low cost.

The study was conducted in two large clinics (providing approximately 44,000 and 53,000 services per year, respectively), two midsize clinics (approximately 15,000 and 21,000 services per year, respectively), and one small clinic (about 10,000 services per year). Large clinics are located in the cities of Tegucigalpa and San Pedro Sula, medium-sized clinics in the towns of Choluteca and La Ceiba, and the small clinic, Belen, is also located in Tegucigalpa. Aside from having the greatest number of clients, large clinics offer the greatest range of services including optometry, dentistry, colposcopy, mammography, ultrasound, and a broader range of other diagnostic tests. Mid-size clinics are similar to large clinics except they serve fewer clients and commonly offer somewhat fewer tests and services. Small clinics have the fewest clients and offer a limited number of services, usually only family planning and general medicine. The clinics were selected to represent ASHONPLAFA's three clinic types.

Intervention: The objective of the screening instrument was to identify services needed by the client and/or her children in addition to the service need that brought her to the clinic. The screening form was a one-page questionnaire. The content of the form varied to reflect the services available in, and the organization of, the different clinics (the Appendix presents a model instrument). It was necessary to produce different screening forms because the types of available services varied by clinic, and the screened services also varied by reason for the visit (e.g., a family planning client would not be screened for an unmet need for contraception).

Dependent variables: Two dependent variables were measured: the ratio of services received per client visit, and the mean revenue per client visit. Data was also collected on the proportion of clients actually screened, and the number and type of unmet service needs encountered during screening. Since services and revenues per visit were not normally distributed, a non-parametric test, the Mann-Whitney U, was used to test for differences between periods.

Procedure: Large and medium clinics have four client contact points while the small clinic has two. Upon entering a clinic, clients go to the appropriate contact point to register for the service desired. A total of 35 staff at the entry points were trained for three hours in the use of the instrument. Data was collected from exit interviews at contact points. Prior to the intervention, clients were only asked the reason they came to the clinic and the number and type of service received. After screening began, clients were asked for their informed consent, whether they had been screened, if any additional service needs had been detected, and the number and type of services received.

Data was collected from three sources: (1) routine service statistics forms; (2) exit interviews of clients leaving the clinics; and (3) screening forms. Service statistics were used to estimate the total number of visits to the study clinics. Since the service statistics system 
does not link expenditures and services received to individual visits, it was necessary to obtain this data from exit interviews. Approximately 800 exit interviews per clinic were conducted during the baseline period and 875 during the endline period. The sample was designed to obtain enough cases for reliable analysis of results. Screening forms were examined to determine the number of clients screened and types of unmet needs detected among clinic users.

Intervention monitoring: Exit interviews conducted with clients helped verify that the intervention was being implemented. The forms were sent to the principal investigator weekly. Also, the principal investigator and her assistant visited the participating clinics every two weeks during the intervention period. During these visits they observed how the screening forms were used and provided feedback to providers.

\section{RESULTS}

Implementation of the experiment: Despite monitoring plans, provider compliance with the intervention was low. The overall proportion of clients screened was less than 11 percent, and the frequency of screening varied greatly by clinic contact point. Table 1 shows screening by clinic and contact point. The table suggests that different types of compliance problems occurred. Besides variation across clinics, there was also large variation by contact point within clinics. In La Ceiba, for example, about 42 percent of eye-care visits were screened, while less than six percent of family planning visits were screened. In many clinics application of screening forms decreased over time. In Belen, the number of visits screened declined from 109 in the first two weeks of the study to only two in the final two weeks, while in San Pedro Sula, the number declined from 138 to 47 over the same period.

Discussions with staff and supervisors suggest that the main reasons for low screening levels included: (1) a heavy client load that made screening impossible during much of the day; (2) patients' lack of interest in being screened; (3) low motivation among some staff members at contact points; (4) high staff turnover at contact points due to vacation or illness; and (5) lack of interest, support, and follow-up by immediate supervisors. 
Table 1. Clients Screened by Clinic and Contact Point

\begin{tabular}{|c|c|c|c|}
\hline Clinic & Clients & No. Screened & Percent Screened \\
\hline \multicolumn{4}{|l|}{ Alameda } \\
\hline Optics & 228 & 0 & 0.0 \\
\hline Lab & 1,561 & 0 & 0.0 \\
\hline Cytology & 1,250 & 0 & 0.0 \\
\hline Counseling/FP/Data entry & 3,401 & 230 & 6.8 \\
\hline Subtotal & 6,440 & 230 & 3.6 \\
\hline \multicolumn{4}{|l|}{ San Pedro Sula } \\
\hline Optics & 197 & 22 & 11.2 \\
\hline Lab & 2683 & 1 & 0.0 \\
\hline Cytology & 1649 & 69 & 4.2 \\
\hline Mammography & 35 & 12 & 34.3 \\
\hline Counseling/FP/Data entry & 2633 & 259 & 9.8 \\
\hline Subtotal & 7,197 & 363 & 5.0 \\
\hline \multicolumn{4}{|l|}{ Choluteca } \\
\hline Optics & 52 & 44 & 84.5 \\
\hline Cytology & 830 & 417 & 50.2 \\
\hline Counseling/FP/Data entry & 724 & 455 & 62.8 \\
\hline Subtotal & 1,606 & 916 & 57.0 \\
\hline \multicolumn{4}{|l|}{ La Ceiba } \\
\hline Optics & 108 & 46 & 42.5 \\
\hline Lab & 1027 & 5 & 0.5 \\
\hline Cytology & 1017 & 183 & 18.0 \\
\hline Counseling/FP/Data entry & 2344 & 140 & 6.0 \\
\hline Subtotal & 4,496 & 374 & 8.3 \\
\hline \multicolumn{4}{|l|}{ Belén } \\
\hline Data Entry/Counseling & 1705 & 422 & 24.8 \\
\hline Subtotal & 1705 & 422 & 24.8 \\
\hline TOTAL & 21,445 & 2,305 & 10.7 \\
\hline
\end{tabular}

$\mathrm{FP}=$ family planning

Equivalence of groups: In participating clinics, 3,991 clients were interviewed preintervention and 4,382 post-intervention. Demographic characteristics of both groups were similar. All respondents were women in union 15-59 years of age. Mean age at baseline and endline surveys was 34 years. Reasons for clinic visits showed little variation between surveys. At baseline, about 85 percent of women visited the clinic for a service for themselves, compared to 88 percent at endline. Cytology was the most frequent service received at both baseline and endline (49\% at each survey), followed by family planning (16\% at each survey), and "general counseling" (9\% at each survey). 
Unmet need and potential demand for ASHONPLAFA services: The baseline survey gathered information on unmet need for prenatal care, contraception, and services for reproductive tract infections, as well as potential service delivery needs among children and spouses. Few women had an unmet need for prenatal care or contraception. Of 254 pregnant women, 88 percent were receiving prenatal care. Approximately 91 percent of the 2,058 women who did not want to get pregnant within the next year were using a contraceptive method. Among women who were contracepting, 11 percent wished to change their method.

The greatest unmet need for reproductive health services was related to potential reproductive tract infections. All women were asked if they had “... any type of problem with their sexual parts for which they would like to see a doctor...” Almost 29 percent of women indicated yes, they would like to see a doctor.

A total of 1,493 women (37\% of interviewees) had children under the age of five. Nearly 60 percent of the children did not attend well child monitoring, but nearly all had the appropriate vaccinations for their ages. Private practitioners, public health centers, and the Honduran Institute of Social Security (IHSS) attend most children receiving services. Overall, 22 percent of respondents had an unmet need for child health services.

The study found a large unmet need for non-reproductive health services among clients and their family members. All interviewees were asked if they or any other family member had a health problem that required medical assistance. Nearly 30 percent of the interviewees mentioned eye problems, and a similar proportion mentioned a need for dental services.

The potential demand for antenatal care and family planning services among ASHONPLAFA clients is small, and the greatest need for reproductive health services is among women who feel they may have a reproductive tract infection. Greater need was found for non-reproductive health services such as routine pediatric care, vision-related services, and dentistry. Since most women attend the clinic unaccompanied, it is unlikely that screening could result in an important increase in services for family members, at least during the visit when screening occurred.

Change in number of services per visit and clinic revenue: As expected from the small number of women screened, there was no overall change in the number of services and amount of revenue collected in the five study clinics. During the pre-intervention period, women received approximately 1.13 services during their visit and spent an average of 150 lempiras (US\$ 7.95) ${ }^{1}$. Post-intervention, women received 1.11 services and spent 149 lempiras (US\$ 7.90). None of the differences are statistically reliable.

Because the frequency of screening in individual clinics ranged from less than four percent to 57 percent, changes were also analyzed on a clinic basis to determine if higher levels of screening were associated with more services per visit and higher revenues. No differences were found by frequency of screening (data not shown).

\footnotetext{
${ }^{1}$ US $\$ 1=18.86$ Honduran lempiras.
} 
Data from exit interviews collected during the post-intervention period were also used to compare services and expenditures at screened visits and the non-screened visits. There was no between-group difference in services or expenditures, with the exception of the mean amount spent. This difference was small in absolute terms (about US \$1.00), and probably cannot be attributed to the intervention since the number of services did not increase. Children of women who were screened obtained no more services than children of women not screened.

Finally, the data from the screening forms was compared to the exit interview responses. Among the 2,305 clients who were screened, 796 additional services were delivered at the same visit. According to this data, screened clients received a mean of 1.35 services per visit, compared to 1.11 as reported in the exit interviews - a difference of 22 percent.

The difference in the two data collection instruments probably accounts for the difference found between the screening forms and exit interviews. For example, the exit questionnaires did not contain a direct question about provider use of the screening form. Rather, the questionnaire asks “... did the provider ask you questions about any other services you might need...?” On the other hand, screening forms were not a part of the official reporting system and not used for accounting purposes. Thus, it is possible that providers over-reported the services they actually provided on the forms to make it appear that they were complying with the intervention.

\section{DISSEMINATION}

Two meetings were conducted to disseminate the results of the project among ASHONPLAFA's staff. The first took place in Tegucigalpa and was attended by the organization's executive director, regional directors, and nineteen staff members from clinics in Tegucigalpa, Juticalpa, and Choluteca. The second meeting took place in San Pedro Sula. The regional directors and the staff of clinics in San Pedro Sula, Santa Rosa de Copán, and La Ceiba attended the second meeting.

\section{UTILIZATION}

The results of the study presented ASHONPLAFA with a difficult decision-making problem. Although the study did not show an increase in the mean number of services per client, the negative results could reasonably be attributed to lack of implementation of the intervention. Moreover, the analysis of the screening forms, unlike the analysis of exit interviews, showed that screened women received more services.

After consultation with the ASHONPLAFA Marketing Department, the executive director ordered that the strategy be implemented in all clinics, along with a system to monitor the utilization of a simplified screening form, designed to be less time consuming and less intrusive than the form tested during the experiment. The new form is limited to services most likely to be needed by clients, as indicated by the study's analysis of unmet need and potential demand. 
Simulated client visits will be used to monitor the implementation of the strategy, and questions regarding screening will be added to the exit interview questionnaires that the association regularly uses to monitor services quality. The organization will also review the monthly service statistics of all clinics, and the newly created Client Service Unit will directly supervise providers.

\section{DISCUSSION}

Unlike the previous six country studies refered to in the introduction, ASHONPLAFA failed to find systematic screening impact. The intervention was not implemented adequately and, as a result, there were no before and after differences in services or revenue per visit. Reasons given by staff for failure to implement systematic screening included crowded services, weak supervision, lack of motivation, and high staff turnover. Frequency of screening in heavily utilized services may be improved by using a shorter form to detect fewer types of unmet service needs. Weak supervision and other motivational problems might be successfully addressed by longer training and by delegating responsibility for screening to a a specific individual in each clinic. The problem of high turnover may be addressed by training a larger number of staff to perform screening.

Client barriers were also encountered. Apparently, many women objected to the number of questions being asked which negatively affected provider use of the forms. This problem may also be solved by the use of shorter, simpler forms. ASHONPLAFA clients have a relatively small unmet need for reproductive health services, and the project might have been more successful had screening emphasized optometry or dentistry.

Provider compliance should become a new focus of operations research. The results of this study indicate that lack of provider compliance was a serious barrier to the successful use of systematic screening and, probably, other job aids as well. 


\section{REFERENCES}

Das, N. P. et al. 2005. "Systematic screening to integrate reproductive health services in India,” FRONTIERS Final Report, Washington, DC: Population Council.

Foreit, James R., Ricardo Vernon, and Patricia Riveros Hamel. 2005. "Use of systematic screening to increase the provision of reproductive health services in Bolivia," FRONTIERS Final Report, Washington, DC: Population Council.

Foreit, Karen G. Fleischman, Karen Hardee, and Kokila Agarwal. 2002. "When does it make sense to consider integrating STI and HIV services with family planning services?” International Family Planning Perspectives 28(2): 105-107.

León, Federico R. et al. 1998. "Increasing use of reproductive health services in a Peruvian clinic,” in Family Planning Operations Research: A Book of Readings, eds. James R. Foreit and Tomas Frejka. New York: Population Council, pp. 239-245.

Sanogo, Diouratié et al. 2005. "Using systematic screening to increase integration of reproductive health services delivery in Senegal,” FRONTIERS Final Report, Washington, DC: Population Council.

Vernon, Ricardo and James Foreit. 1999. "How to help clients obtain more preventative reproductive health care,” International Family Planning Perspectives 25(4): 200-202. 


\section{APPENDIX}

Illustrative Systematic Screening Checklist To Detect Reproductive Health Services Needed 


\begin{tabular}{|c|c|c|c|c|}
\hline \multirow{2}{*}{1.} & \multicolumn{4}{|l|}{ How old are you? } \\
\hline & \multicolumn{2}{|l|}{ SCREENING QUESTIONS } & \multirow{2}{*}{\begin{tabular}{|l|} 
SERVICE \\
REQUIRED \\
PAP SMEAR
\end{tabular}} & \multirow{2}{*}{\begin{tabular}{|l|}
$\begin{array}{r}\text { ACTION } \\
\text { TAKEN }\end{array}$ \\
1. Delivered \\
2. Appointment \\
3. Referred
\end{tabular}} \\
\hline 2. & $\begin{array}{l}\text { Have you had a Pap smear or cervical } \\
\text { cancer detection test in the last year? } \\
\text { NO ------------- }\end{array}$ & $\begin{array}{l}\text { Would you like to have } \\
\text { the test today? }\end{array}$ & & \\
\hline 3. & $\begin{array}{l}\text { Have you visited a gynecologist in } \\
\text { the last year to have a breast exam to } \\
\text { prevent breast cancer? } \\
\text { NO ------------- } \rightarrow\end{array}$ & $\begin{array}{l}\text { Would you like to have } \\
\text { the exam today? }\end{array}$ & $\begin{array}{l}\text { MANUAL BREAST } \\
\text { EXAMINATION }\end{array}$ & $\begin{array}{l}\text { 1. Delivered } \\
\text { 2. Appointment } \\
\text { 3. Referred }\end{array}$ \\
\hline 4. & $\begin{array}{l}\text { Do you have vaginal flow, burning } \\
\text { sensation, itching, pain or some other } \\
\text { symptom in your genitals for which } \\
\text { you would like to see the } \\
\text { gynecologist? } \\
\qquad \text { YES -------------- } \rightarrow\end{array}$ & $\begin{array}{l}\text { Would you like to see } \\
\text { the gynecologist today? }\end{array}$ & $\begin{array}{l}\text { GYNECOLOGICAL } \\
\text { CONSULTATION }\end{array}$ & $\begin{array}{l}\text { 1. Delivered } \\
\text { 2. Appointment } \\
\text { 3. Referred }\end{array}$ \\
\hline 5. & $\begin{array}{l}\text { Are you pregnant? } \\
\qquad \text { YES ------------ } \rightarrow\end{array}$ & $\begin{array}{l}\text { Are you attending } \\
\text { prenatal care? } \\
\text { YES NO ----- } \rightarrow\end{array}$ & $\begin{array}{l}\text { Would you like to } \\
\text { attend prenatal care } \\
\text { today? } \\
\text { (Go to } 7)\end{array}$ & $\begin{array}{l}\text { 1. Delivered } \\
\text { 2. Appointment } \\
\text { 3. Referred }\end{array}$ \\
\hline 6. & 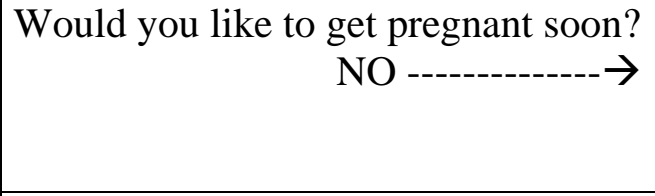 & $\begin{array}{l}\text { Are you using a } \\
\text { contraceptive method? } \\
\text { NO ---- } \rightarrow\end{array}$ & $\begin{array}{l}\text { Would you like to } \\
\text { have a FAMILY } \\
\text { PLANNING } \\
\text { consultation? }\end{array}$ & $\begin{array}{l}\text { 1. Delivered } \\
\text { 2. Appointment } \\
\text { 3. Referred }\end{array}$ \\
\hline 7. & $\begin{array}{l}\text { Do you have any children under } 5 \text { ? } \\
\text { YES ------------ } \rightarrow\end{array}$ & $\begin{array}{l}\text { Are you taking them in } \\
\text { for healthy child } \\
\text { control and growth } \\
\text { monitoring? } \\
\qquad \text { NO ---- } \rightarrow\end{array}$ & $\begin{array}{l}\text { Would you like them } \\
\text { to have a pediatrics } \\
\text { consultation today or } \\
\text { schedule an } \\
\text { appointment? } \\
\end{array}$ & $\begin{array}{l}\text { 1. Delivered } \\
\text { 2. Appointment } \\
\text { 3. Referred }\end{array}$ \\
\hline 8. & $\begin{array}{l}\text { Have you had your teeth checked out } \\
\text { for cavities by a dentist in the last } \\
\text { three years? } \\
\qquad \text { NO -------------- } \rightarrow\end{array}$ & $\begin{array}{l}\text { Would you like to see a } \\
\text { dentist during your visit } \\
\text { today? } \\
\text { YES --- } \rightarrow\end{array}$ & DENTISTRY & $\begin{array}{l}\text { 1. Delivered } \\
\text { 2. Appointment } \\
\text { 3. Referred }\end{array}$ \\
\hline 9. & $\begin{array}{l}\text { Is there any other service you would } \\
\text { like to receive today, or would like to } \\
\text { be referred for? } \\
\text { YES------------- } \rightarrow\end{array}$ & List service & OTHER SERVICE & $\begin{array}{l}\text { 1. Delivered } \\
\text { 2. Appointment } \\
\text { 3. Referred }\end{array}$ \\
\hline
\end{tabular}

